\title{
HLA Class II Alpha Chain Gene Polymorphisms in Patients with Insulin- dependent Diabetes Mellitus, Dermatitis Herpetiformis, and Celiac Disease
}

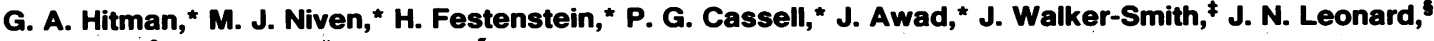 \\ Lionel Fry, P. Ciclitira, $\|$ P. Kumar,' and J. A. Sachs* \\ *The Medical Unit, Department of Immunology, and Bone and Joint Research Unit, The London Hospital Medical College, Whitechapel, \\ London, E1 1BB; ${ }^{\ddagger}$ Department of Gastroenterology, Queen Elizabeth Hospital, London, E.2; ${ }^{\S}$ Department \\ of Dermatology, St. Mary's Hospital, London, W.2; \|Department of Medicine, The Rayne Institute, St. Thomas' Hospital, London, S.E.1; \\ 'Department of Gastroenterology, St. Bartholomew's Hospital, London, England E.C.I
}

\begin{abstract}
We have investigated DNA polymorphism of the class II $\alpha$ chain genes in HLA typed patients with insulin dependent diabetes mellitus (IDDM; $n=79$ ), celiac disease (CD; $n=46)$, dermatitis herpetiformis (DH; $n=53)$, and controls $(n=86)$. Preferential allelic associations of HLA genes and gene products have thus been constructed for susceptibility to these diseases. DR $\alpha$ and DQ $\alpha$ gene polymorphisms indicated heterogeneity of HLA DR3, DRw6, and DR7, and HLA DR2 and DRw6, respectively. In DR7 positive CD patients a 3.8-kilobase (kb) $\mathrm{DR} \alpha$ fragment, which correlated with DQw3, was found in only $11 \%$ of patients compared with $45 \%$ of corresponding controls $(P<0.05)$. An increased frequency of a DX $\alpha$ genotype $\mathrm{UU}$ in all three diseases was found (IDDM 59\%, DH 45\%, CD $48 \%$, compared to $21 \%$ in controls, $P<0.001$, which is not explained solely by the increased frequencies of DR3-DX $\alpha \mathrm{U}$. We therefore conclude part of the genetic susceptibility for these three conditions is encoded by genes within the DQ-DX subregion.
\end{abstract}

\section{Introduction}

Genes determining susceptibility or resistance to a variety of diseases have been localized to the HLA region on chromosome 6. Individual serologically defined HLA antigens were initially shown to be increased in frequency in groups of patients when compared to healthy controls from the same population group. In insulin dependent diabetes mellitus (IDDM), ${ }^{1}$ dermatitis herpetiformis $(\mathrm{DH})$, and celiac disease $(\mathrm{CD})$, statistically significant associations are found with HLA-DR3; in addition the frequency of DR4 is increased in IDDM (1-3), DR2 in DH (4), and DR7 in $\mathrm{CD}(5,6)$. Since a proportion of patients with these conditions do not have the relevant antigens, the likelihood is that the genes encoding them are not those conferring the disease susceptibility, but are markers for other closely linked genes. Even after more

Address reprint requests to Dr. Hitman, Medical Unit, The London Hospital, Whitechapel, London, E1 1BB. 1986

Received for publication 16 July 1986 and in revised form 16 October

1. Abbreviations used in this paper: $\mathrm{CD}$, celiac disease; $\mathrm{DH}$, dermatitis herpetiformis; IDDM, insulin-dependent (type 1) diabetes mellitus; MHC, major histocompatibility complex; RFLP, restriction fragment length polymorphism.

J. Clin. Invest.

(C) The American Society for Clinical Investigation, Inc.

0021-9738/87/02/0609/07 \$1.00

Volume 79, February 1987, 609-615 detailed examination of other major histocompatibility complex (MHC) gene products, such as the class II HLA DQ series (7), the lymphocyte activating HLA-Dw determinants (8) and the complement components $\mathrm{C} 2, \mathrm{C} 4$ and $\mathrm{Bf}(9)$, none appear to be invariably present, although some combinations of several closely linked gene products show clearer associations than individual antigens. For example the associations of the complement component $\mathrm{C} 4 \mathrm{AQ} 0$ with DR3, or C4AB3 with DR4 are more significant in IDDM patients compared to controls than each antigen taken individually. Additionally, some evidence has been presented that non-MHC genes may be involved in these diseases. In IDDM associations have been described with the class 1 allele adjacent to the insulin gene located on chromosome 11 $(10,11)$ and the $\beta$-chain of the T cell receptor on chromosome 7 (12). In celiac disease an association has been described with heavy chain immunoglobulin $(\mathrm{Gm})$ allotypes (13).

Analysis of the MHC has thus been mainly confined to detection of serologically defined antigenic determinants. More recent analysis at the genomic level has defined heterogeneity within serological specificities. Thus the search for the disease susceptibility genes within the HLA-class II region has been extended by detection and comparison of restriction fragment length polymorphisms (RFLP) in patients and healthy control populations. The HLA-D region consists of three main adjacent subregions (Fig. 1). The HLA DR locus consists of three $\beta$-chain genes and an $\alpha$-chain gene. The DQ region consists of a single $\alpha$ - and $\beta$-chain gene at both the DQ and DX loci. The DP subregion consists of two $\alpha$-chain genes and two $\beta$-chain genes. Marked differences in frequency of various RFLPs within the HLA D region have been described in HLA serologically matched patients and controls. Owerbach et al. 1983 (14) found a decreased prevalence of a Bam $\mathrm{HI} 3.7 \mathrm{~kb}$ DQ $\beta$ related fragment in IDDM ( $2 \%$ in IDDM subjects compared with $27 \%$ controls). Subsequently, Festenstein et al. (15) and Cohen-Haguenauer et al. (16) found an increase in certain $\mathrm{DQ} \beta$ RFLPs (designated as omega and DQR4, respectively) in IDDM subjects who possess DR4.

As the class II molecule consists of both an $\alpha$ - and $\beta$-chain we felt it would be equally important to study $\alpha$-chain polymorphism in relation to autoimmune disease. We were especially interested in studying the DX $\alpha$ locus at the genomic level as no expression has been detected in the cell lines so far studied despite an apparently normal gene structure based on nucleotide sequencing (17). We have previously demonstrated an increased frequency of a Taq $1 \mathrm{DX} \alpha$ gene related fragment sized $2.1 \mathrm{~kb}$ (U allele) in IDDM patients compared with healthy controls using a genomic $\mathrm{DQ} \alpha$ probe (18). The $\mathrm{DQ} \alpha$ probe also identifies the $\mathrm{DX} \alpha$ gene because of close nucleotide homology between these two loci (17). This study (a) provides additional information on DR associations in individuals with the UU genotype in 

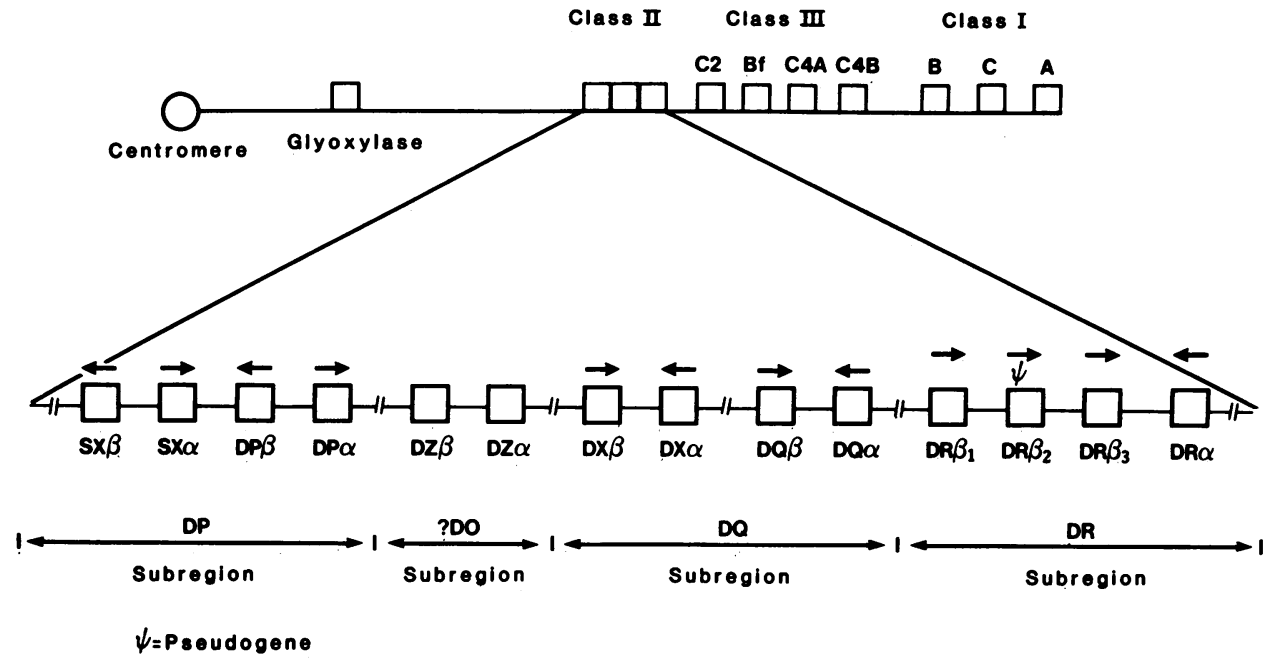

Figure 1. Map of Class II MHC genes on the short arm of chromosome 6 (taken from reference 30). The exact orientation of individual genes with respect to each other is not exactly known, although the direction of transcription is indicated by the arrows. The location of the DO subregion is not known and may be telomeric to the DR subregion rather than between the DP and $\mathrm{DQ}$ subregions as shown in this diagram.
IDDM; $(b)$ compares the distribution of DX $\alpha$ and DQ $\alpha$ RFLPs in patients with IDDM, CD and DH and healthy controls; (c) analyses the distribution of DR $\alpha$ RFLPs in the four population groups; $(d)$ defines preferential allelic associations in the four population groups.

\section{Methods}

Subjects. Unrelated British Caucasian healthy individuals with no known personal or family history of diabetes mellitus, celiac disease, or dermatitis herpetiformis served as controls for RFLP studies. A reference control panel $(n=161)(19)$ was used for comparison of DR and DQw antigen frequencies with the patient groups. Some of the unrelated British Caucasian IDDM subjects were those previously described (10). Unrelated British Caucasian patients with celiac disease and dermatitis herpetiformis were serially selected from outpatient clinics and most of them were described in a previous study (4). 86 healthy controls, 79 patients with IDDM, 53 with DH, and 46 with CD were analyzed.

DNA analysis. DNA was extracted by a modification of the method of Kunkel from leukocytes obtained from whole blood samples anticoagulated with EDTA and previously stored at $-20^{\circ} \mathrm{C}(20)$. After digestion with the appropriate restriction enzyme according to manufacturers specifications (Boehringer Mannheim, Cambridge, England; Anglian Biotechnology Ltd., Colchester, England) DNA fragments were separated by electrophoresis on a $0.85 \%$ agarose gel and then transferred to a nylon membrane (Gene Screen Plus; New England Nuclear Research Products, Boston, MA) using an alkaline solvent (21). Hybridization with nick translated ${ }^{32} \mathrm{P}$-labeled gene probes was performed according to a standard protocol (New England Nuclear Research Products). All filters were washed down to a high stringency as recommended by the manufacturers and exposed to Kodak XAR5 film in the presence of two high speed intensifying screens for $36 \mathrm{~h}$ at $-70^{\circ} \mathrm{C}$. Hybridization bands were sized by comparison with an internal control (GAH genomic DNA) and Hind III digested lambda phage (Bethesda Research Laboratories, Paisley, Scotland) present on each filter. GAH genomic DNA allowed standardization of sizes of alleles between autoradiograms and also acted as an internal control for adequacy of DNA digestion. The genomic $\mathrm{DQ} \alpha(22)$ and the cDNA DR $\alpha$ (23) probes used were kind gifts of J. Trowsdale and W. Bodmer (London, England) and P. A. Peterson (Uppsala, Sweden), respectively.

HLA typing. Tissue typing for HLA-A, -B, -C (24), -DR, and -DQ antigens (25) was performed according to previously described techniques. All subjects were typed for HLA-A, $-\mathrm{B},-\mathrm{C}$, and -DR antigens; 54 subjects with IDDM and 12 with $C D$ were not typed for $D Q$ antigens. It was also not always possible to identify the $D Q w 2$ antigen in individuals who were both DR3 and DR7 as appropriate absorbed antisera were not available.
Statistical methods. Serological and RFLP data were analyzed for differences in allelic or genotype frequencies by chi-square tests using 2 $\times 2,3 \times 2$, or $5 \times 2$ contingency tables.

\section{Results}

\section{HLA-DR frequencies}

The HLA-DR frequencies (Table I) in the RFLP control panel and HLA-DR reference panel were similar. As expected the frequency of DR3 is highly significantly raised in all three patient groups $(P<0.001)$ compared with the HLA-DR reference panel. The frequency of DR4 $(P<0.001)$ and the heterozygote DR3/ DR4 $(P<0.001)$ were also significantly increased in IDDM compared to the controls. Similarly DR7 is increased in the CD panel when compared to all three other panels $(P<0.001)$. No

Table I. Distribution of DR Frequencies in Different Groups

\begin{tabular}{lllllc}
\hline $\begin{array}{l}\text { DR } \\
\text { antigen }\end{array}$ & $\begin{array}{l}\text { HLA reference } \\
\text { control panel } \\
(n=161)\end{array}$ & $\begin{array}{l}\text { RFLP } \\
\text { controls } \\
(n=86)\end{array}$ & $\begin{array}{l}\text { IDDM } \\
(n=79)\end{array}$ & $\begin{array}{l}\text { DH } \\
(n=53)\end{array}$ & $\begin{array}{l}\text { CD } \\
(n=46)\end{array}$ \\
\hline & Percent & Percent & Percent & Percent & Percent \\
DR1 & 16 & 19 & 15 & 11 & $0^{*}$ \\
DR2 & 32 & 27 & $6^{\ddagger}$ & 26 & $13^{*}$ \\
DR3 & 32 & 34 & $63^{\ddagger}$ & $80^{\ddagger}$ & $89^{\ddagger}$ \\
DR4 & 37 & 34 & $71^{\ddagger}$ & 28 & $6^{\ddagger}$ \\
DR5 & 14 & 14 & 4 & 4 & 2 \\
DRw6 & 19 & 16 & 9 & 9 & 9 \\
DR7 & 27 & 30 & 9 & 22 & $54^{\ddagger}$ \\
DR3/2 & 6 & 7 & 2 & $26^{\ddagger}$ & 0 \\
DR3/4 & 9 & 9 & $37^{\ddagger}$ & 11 & 2 \\
DR3/7 & 8 & 7 & $0^{*}$ & 15 & $48^{\ddagger}$ \\
DR3/X & 2 & 1 & 4 & 0 & 11 \\
DR4/X & 4 & 2 & 6 & 6 & 2 \\
DR7/X & 2 & 2 & 0 & 0 & 2 \\
\hline
\end{tabular}

$\mathrm{X}$, no other antigen detected implying homozygosity.

$P$ values were calculated from $2 \times 2$ contingency tables by chi-square analysis for comparison of patients with the HLA reference control panel.

${ }^{*} P<0.05 ;{ }^{\ddagger} P<0.001$. 
significant difference was seen in frequency of DR2 in controls and patients with DH in this study although the DR3/DR2 heterozygotes were significantly increased in patients compared with controls ( 26 vs $6 \% ; P<0.001)$.

\section{$H L A-D Q$ frequencies}

The frequency of DQw2 was increased (in association with the increase of DR3) in all three disease groups compared to the control group $(P<0.001$; data not shown). The frequencies of $D Q w 1$ and $D Q w 3$ were examined only in individuals who were DR3 (Table II). Compared to the reference control panel DQw1 was decreased in IDDM patients $(P<0.01)$ and increased in DH patients $(P<0.05)$. The frequency of DQw3 was markedly decreased $(P<0.001)$ in patients with CD and DH. By subtracting from 100 the $D Q w 1$ and $D Q w 3$ percentages in individuals who are DR3 DQw2, the frequency of DQw2 with a second DR antigen (predominantly DR7) was determined. This revealed that DQw2 occurred with a second DR antigen in $10 \%$ of controls compared with $17 \%$ of IDDM patients $(P=\mathrm{NS}), 28 \%$ of DH patients $(P<0.05)$ and $62 \%$ of $C D$ patients $(P<0.001)$.

When the DQ association in DR7 individuals is analyzed, 9/24 RFLP controls are DQw3 associated compared to 0/8 IDDM, $2 / 25 \mathrm{CD}$, and $0 / 11 \mathrm{DH}$ patients $(P<0.05$ for all comparisons).

\section{$D Q \alpha$ polymorphism}

Using the $\mathrm{DQ} \alpha$ genomic probe five $\mathrm{DQ} \alpha$ Taq I fragments sized 6.8, 6.2, 5.5, 4.6, and $2.6 \mathrm{~kb}$ were detected (Fig. 2) (Table III). In all subjects studied the $5.5-\mathrm{kb}$ fragment is associated with DR4 and DR7, and $4.6 \mathrm{~kb}$ with DR3 and DR5 (irrespective of their different $\mathrm{DQw}$ associations). The $2.6-\mathrm{kb}$ fragment was present in 22/23 DR1 individuals. One DR2, and two DRw6 individuals both without DRI also had the $2.6-\mathrm{kb}$ band. In all others, DR2 and DRw6 associated with either the 6.8 or the 6.2$\mathrm{kb}$ fragments. Thus 18/21 (86\%) DR2 controls and 10/14 (71\%) DR2 DH patients $(P=\mathrm{NS})$ have the $6.2-\mathrm{kb}$ fragment as do $2 / 8$ controls, 6/6 DRw6 IDDM $(P<0.05), 4 / 4$ DRw6 DH, and 1/6 DRw6 CD patients.

\section{DX $\alpha$ polymorphism}

The DQ $\alpha$ probe also hybridizes with two Taq I allelic DX $\alpha$ fragments sized $2.1 \mathrm{~kb}$ (U for upper) and $1.9 \mathrm{~kb}$ ( $\mathrm{L}$ for lower) (Fig. 1) because of close nucleotide homology between the two loci (17). The frequencies of homozygotes of the $U$ and $L$ alleles and heterozygotes for both alleles, according to DR phenotypes are given for the different groups in Table IV.

Based on the incidence of individuals homozygous for $U$ or $\mathrm{L}$, and their DR type, in the control subjects the U allele tends to coinherit with DR2, DR3, DRw6, and the L allele with DR1, DR4, DR5, and DR7 (Table IV).

\section{$D X \alpha$ in IDDM}

In IDDM patients the frequency of UU is considerably increased and that of LL considerably decreased when compared with the control distribution (Table III) $(P<0.001)$. This reflects the DR3-U association obtained in controls as well as the high correlation of DR4 with the $U$ allele in IDDM in contrast to the $\mathrm{L}$ allele in controls: of the 24 DR4 patients who are not DR3, 12 $(50 \%)$ are UU and only $5(21 \%)$ are LL; of the corresponding 30 controls, $3(10 \%)$ are UU and $16(53 \%)$ are LL $(P<0.01)$. By the same token, not withstanding the strong association of the $U$ allele with all DR3 individuals, the distribution of the $U$ and $\mathrm{L}$ alleles in DR3/4 IDDM patients is significantly different $(P<0.05)$ from that of DR3/4 controls (see Table IV).

\section{$D X \alpha$ in $D H$}

In DH an increased frequency of UU $(45 \%)$ is found with a corresponding decrease of the LL genotype (8\%) compared with 21 and 34\%, respectively, in controls $(P<0.001)$ (Table III), which is partly explained by the increased prevalence of $U$ associated DR3 in the patient group. There is no clearcut association between the $U$ allele and other DR antigens.

\section{$D X \alpha$ in $C D$}

In CD patients $48 \%$ have the UU genotype and only $15 \%$ the LL genotype compared to 21 and $34 \%$, respectively, in controls $(P<0.001)$ (Table III). This is partly due to the increase in the $\mathrm{U}$ associated DR3 as well as the nonsignificant increase in the U-DR7 association when compared to the controls (Table IV).

\section{$D R \alpha$ polymorphism}

Using a DR $\alpha$ cDNA probe with restriction enzyme Bgl II, three different fragments, $4.5 \mathrm{~kb}, 4.2 \mathrm{~kb}$, and $3.8 \mathrm{~kb}$, were identified (Fig. 3). A fourth band, $0.7 \mathrm{~kb}$, always appeared together with the $3.8-\mathrm{kb}$ band. No more than two of the three large fragments were found in each individual. Individuals who possess DR2, DR4, and DR5 always had the 4.5-kb fragment and DR1 individuals always had the $3.8-\mathrm{kb}$ fragment. In contrast, individuals possessing DR3, DRw6, or DR7 were heterogeneous with respect to the DR $\alpha$ RFLP (Table V).

$D R 3$ polymorphism. 90 percent of all $\mathrm{DR} 3$ individuals had the $4.2-\mathrm{kb}$ fragment and the $4.5-\mathrm{kb}$ fragment was present in the remainder (Table V). There was no significant difference in their distribution in the individual population groups.

DRw6 polymorphism. DRw6 (both DRw13 and DRw14) associated with either the $4.5-$ or $4.2-\mathrm{kb}$ fragment.

DR7 polymorphism. Individuals with DR7 possessed either the 3.8 or $4.5-\mathrm{kb}$ fragment. The $3.8-\mathrm{kb}$ fragment was present in 6/14 (43\%) controls compared with $2 / 17$ (12\%) patients with $\mathrm{CD}(P<0.05), 0 / 7$ with DH and 0/4 with IDDM. Although it was not possible to determine the DQ typings in some subjects,

Table II. Frequency Distribution of the Second DQ Antigen in Individuals Who Are Positive for DR3 and DQw2

\begin{tabular}{lllrrr}
\hline & $\begin{array}{l}\text { Reference } \\
\text { panel }\end{array}$ & \multicolumn{1}{l}{$\begin{array}{l}\text { RFLP } \\
\text { controls }\end{array}$} & IDDM & DH & CD \\
\hline DQw1 & $17 / 51(31)^{*}$ & $13 / 37(35)$ & $7 / 48^{\ddagger}(15)$ & $23 / 43^{8}(53)$ & $12 / 42(29)$ \\
DQw3 & $30 / 51(59)$ & $17 / 37(46)$ & $33 / 48(69)$ & $7 / 43^{\prime \prime}(16)$ & $4 / 42^{\prime \prime}(10)$ \\
DQw2 (calculated) & $5 / 41(10)$ & $7 / 37(19)$ & $8 / 48(17)$ & $13 / 43(30)$ & $26 / 42^{\prime \prime}(62)$ \\
\end{tabular}

$P$ values were calculated from $2 \times 2$ contingency tables by chi-square analysis for comparison of patients with HLA reference control panel.

${ }^{*}$ Percentages in parentheses. ${ }^{\ddagger} P<0.05 ;{ }^{8} P<0.01$; $"$ " $P<0.001$. 


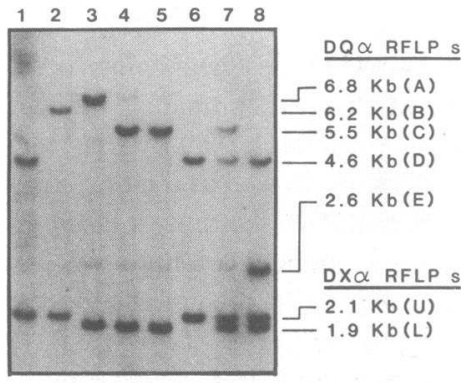

UU UU LL LL LL UU UL UL GENOTYPE
Figure 2. Autoradiogram of $\mathrm{DQ} \alpha$ and $\mathrm{DX} \alpha$ restriction fragment length polymorphisms. DNA from 8 individuals (labeled 1-8) was digested with Taq 1 and studied by Southern blot hybridization methods using a genomic DQ $\alpha$ gene probe. This probe also detects DX $\alpha$ genomic sequences because of the close nucleotide homology between the $\mathrm{DQ} \alpha$ and $\mathrm{DX} \alpha$ genes (17).

DQw3 always occurred in those patients with the 3.8-kb fragment and not in those with the $4.5-\mathrm{kb}$ fragment.

\section{Preferential allelic associations}

Based on the serologically defined class I and class II antigens, and RFLPs obtained with the Taq 1 restriction enzyme and the $\mathrm{DQ} \alpha$ probe and with $\mathrm{Bgl}$ II restriction enzyme and the DR $\alpha$ probe, the following HLA haplotype constructs could be derived (Table VI):

(a) $(\mathrm{A} 1-\mathrm{B} 8)=\mathrm{DR} 3=\mathrm{DQw} 2=\mathrm{DQ} \alpha-4.6 \mathrm{~kb}=\mathrm{DX} \alpha-2.1 \mathrm{~kb}$ $=\mathrm{DR} \alpha-4.2 \mathrm{~kb}$ occurs in all four population groups and its increased frequency in DH, CD, and IDDM is concomitant with the increased association previously found with DR3 in these three conditions.

(b) $(\mathrm{A} 3-\mathrm{B} 7)=\mathrm{DR} 2=\mathrm{DQw} 1=\mathrm{DQ} \alpha-6.2 \mathrm{~kb}=\mathrm{DX} \alpha-2.1 \mathrm{~kb}$ $=\mathrm{DR} \alpha-4.5 \mathrm{~kb}$ occurs frequently in the controls and patients with DH. The DQ $\alpha$ 6.8-kb fragment occurs instead of the 6.2kb fragment in $\sim 25 \%$ of both groups.

(c) $\mathrm{DR} 4=\mathrm{DQw} 3=\mathrm{DQ} \alpha-5.5 \mathrm{~kb}=\mathrm{DX} \alpha-1.9 \mathrm{~kb}=\mathrm{DR} \alpha-$ $4.5 \mathrm{~kb}$ was unequivocally assigned in $17 / 22 \mathrm{DR} 4$ control individuals and 4/34 IDDM patients, whereas DR4 = DQw3 $=\mathrm{DQ} \alpha-5.5 \mathrm{~kb}=\mathrm{DX} \alpha-2.1 \mathrm{~kb}=\mathrm{DR} \alpha-4.5 \mathrm{~kb}$ was assigned to $5 /$ 22 controls and 30/34 IDDM patients.

(d) DRw6 = DQw1 = DQ $\alpha-6.8 \mathrm{~kb}=\mathrm{DX} \alpha-2.1 \mathrm{~kb}=\mathrm{DR} \alpha-$ 4.5 kb was found in 6/7 controls whereas DRw6 $=\mathrm{DQw} 1$ $=\mathrm{DQ} \alpha-6.2 \mathrm{~kb}=\mathrm{DX} \alpha-2.1 \mathrm{~kb}$ was found in 6/7 IDDM patients (the rogue fragment was DQ $\alpha 2.6 \mathrm{~kb}$ ) and 4/5 tested for DR $\alpha$ had the 4.2-kb band. The five IDDM patients that were DR4/ w6 had the same profiles DR4 $=\mathrm{DQw} 3=\mathrm{DQ} \alpha-5.5 \mathrm{~kb}=\mathrm{DX} \alpha$ $2.1 \mathrm{~kb}=\mathrm{DR} \alpha-4.5 \mathrm{~kb}$ DRw6 $=\mathrm{DQw1}=\mathrm{DQ} \alpha-6.2 \mathrm{~kb}=\mathrm{DX} \alpha-$ $2.1 \mathrm{~kb}$. Four had the $\mathrm{DR} \alpha-4.2-\mathrm{kb}$ fragment as well. (e) (B57) $=$ DR7 = DQw3 $=$ DQ $\alpha-5.5 \mathrm{~kb}=\mathrm{DX} \alpha-1.9 \mathrm{~kb}$ $=\mathrm{DR} \alpha-3.8 \mathrm{~kb}$ profile was found in 6/14 controls and only $2 /$ 29 of all patients, whereas DR7 $=\mathrm{DQw2}=\mathrm{DQ} \alpha-5.5 \mathrm{~kb}=\mathrm{DX} \alpha-$ 1.9/2.1 kb $=D R \alpha-4.5 \mathrm{~kb}$ was found in all the other DR7 patients and controls.

\section{Discussion}

Results from this study suggest that some disease associated susceptibility genes previously attributed to the DR region are associated with genes within or centromeric to the DQ and DX MHC region.

The frequencies of the relevant serologically defined HLADR antigens in our RFLP control group are similar to those of the DR reference control group. The increased frequencies of DR3 and DR4 in IDDM, DR3, and DR7 in CD, and DR3 in $\mathrm{DH}$ are similar to other studies. In DH no difference was found in DR2 frequency compared with controls but the DR3/DR2 heterozygote and $\mathrm{DQw} 1$ were significantly increased. In a larger group of DH patients $(n=70)$ both DQw $1(P<0.05)$ and DR2 $(P<0.05)$ were increased (unpublished observations). These data are consistent with the current view that in all three diseases at least one disease susceptibility gene is associated with one HLA haplotype and another with the second haplotype specifically DR3 and DR4 in IDDM, DR3 and DQw1/DR2 in DH, and DR3 and DR7 in CD. It is interesting to note that in CD the DQw2 antigen is possibly more important for susceptibility DR3 and/or DR7, confirming the findings of Tosi et al. (26). Thus in DH and CD the serological data is consistent with the view that at least for one haplotype the susceptibility gene resides closer to DQ than DR. The increase of DQw3 in IDDM patients (Table III) can be correlated with the increase of the DR4 antigen with which it is in linkage disequilibrium. It is not possible to allocate the DR4 susceptibility gene in IDDM to either the DR or DQ region using standard serological criteria alone.

RFLPs have been identified with $\mathrm{DR} \alpha$ and $\mathrm{DQ} \alpha$ probes in the four different population groups of similar ethnic origin. $\mathrm{DR} \alpha$ polymorphisms have been previously reported both at the protein (27) and the genomic level (28). The increased frequency of the DR $\alpha$ 4.2-kb fragment found in all three diseases reflected the increase of DR3. Heterogeneity of DR3 has also been defined by HLA-B serology. It was therefore of interest that the DR $\alpha$ RFLP did not preferentially associate with B8 which is DR3 associated in this British Caucasian population. Only three individuals were B18-DR3 of which two were DR $\alpha-4.2$ and one

Table III. DX,$D Q \alpha$, and DR $\alpha$ Polymorphisms in Controls, and Patients with IDDM, DH, and CD

\begin{tabular}{|c|c|c|c|c|c|c|c|c|c|c|c|c|c|}
\hline \multirow[b]{2}{*}{ Group } & & \multicolumn{3}{|l|}{$\mathrm{DX} \alpha$} & \multicolumn{5}{|l|}{ DQ $\alpha$} & & \multicolumn{3}{|l|}{$\mathrm{DR} \alpha$} \\
\hline & & UU & LL & UL & 6.8 & 6.2 & 5.5 & 4.6 & 2.6 & & 4.5 & 4.2 & 3.8 \\
\hline & & Percent & Percent & Percent & Percent & Percent & Percent & Percent & Percent & & Percent & Percent & Percent \\
\hline Con & $n=86$ & 21 & 34 & 45 & 13 & 27 & 66 & 42 & 26 & $n=53$ & 91 & 42 & 30 \\
\hline IDDM & $n=79$ & 59 & 8 & $32^{*}$ & 3 & 13 & 81 & 68 & $18^{\ddagger}$ & $n=50$ & 86 & 56 & 20 (NS) \\
\hline DH & $n=54$ & 45 & 8 & $47^{*}$ & 7 & 30 & 46 & 83 & $13^{\ddagger}$ & $n=36$ & 83 & 78 & $8^{\ddagger}$ \\
\hline CD & $n=46$ & 48 & 15 & $37^{\ddagger}$ & 8 & 9 & 59 & 93 & $2^{*}$ & $n=31$ & 81 & 84 & $6^{\ddagger}$ \\
\hline
\end{tabular}

$P$ values were calculated from $3 \times 2$ and $5 \times 2$ contingency tables by chi-square analysis for comparison of patients with controls. ${ }^{*} P<0.001$; $\ddagger P<0.01$. 
Table IV. Distribution of DXa $2.1 \mathrm{~kb}(U)$ and $1.9(\mathrm{~L}) \mathrm{kb}$ Polymorphisms

\begin{tabular}{|c|c|c|c|c|c|c|c|c|c|c|c|c|}
\hline \multirow{2}{*}{$\begin{array}{l}\text { DR } \\
\text { antigen }\end{array}$} & \multicolumn{3}{|c|}{ Controls $(n=86)$} & \multicolumn{3}{|c|}{$\operatorname{IDDM}(n=79)$} & \multicolumn{3}{|c|}{$\mathrm{DH}(n=53)$} & \multicolumn{3}{|c|}{$\mathrm{CD}(n=46)$} \\
\hline & UU & LL & UL & UU & $\mathbf{L L}$ & UL & UU & $\mathbf{L L}$ & UL & UU & $\mathbf{L L}$ & UL \\
\hline DR1 & 0 & 8 & 8 & 2 & 3 & 7 & 2 & 0 & 2 & - & - & - \\
\hline DR2 & 10 & 3 & 11 & 2 & 0 & 3 & 12 & 0 & 2 & 3 & 0 & 2 \\
\hline DR3 & 9 & 2 & 17 & 34 & 1 & $16^{*}$ & 22 & 0 & 20 & 14 & 4 & 11 \\
\hline DR4 & 2 & 16 & 17 & 36 & 6 & $15^{\ddagger}$ & 3 & 2 & 10 & 0 & 0 & 1 \\
\hline DR5 & 0 & 4 & 3 & 0 & 0 & 3 & 0 & 1 & 0 & 0 & 0 & 0 \\
\hline DR6 & 5 & 0 & 2 & 7 & 0 & 0 & 2 & 0 & 3 & 5 & 0 & 1 \\
\hline DR7 & 3 & 10 & 12 & 2 & 1 & 5 & 1 & 2 & 8 & 6 & 6 & 11 \\
\hline DR3/2 & 4 & - & 2 & 1 & - & 1 & 12 & - & 2 & 3 & - & 3 \\
\hline DR3/4 & 2 & 1 & 5 & 24 & 1 & $7^{8}$ & 1 & - & 5 & & & \\
\hline DR3/7 & 2 & - & 4 & 1 & - & 5 & 1 & 2 & 8 & 5 & 3 & 11 \\
\hline DR3/X & - & - & 1 & 3 & - & - & 4 & - & - & 4 & - & - \\
\hline DR4/X & - & 1 & 1 & 4 & 1 & - & 2 & - & 1 & - & - & - \\
\hline
\end{tabular}

$\mathrm{X}$, no other antigen detected implying homozygosity. $P$ values were calculated from $3 \times 2$ contingency tables by chi-square analysis for comparison of patients with controls. ${ }^{*} P<0.01 ;{ }^{\ddagger} P<0.001 ;{ }^{\circledR} P<0.05$.

DR $\alpha 4.5$. We are unable to confirm the recently reported findings of Stetler et al. (28) who found $16 \%$ of 55 controls compared with $50 \%$ of 12 IDDM probands positive for the DR $\alpha 4.2-\mathrm{kb}$ allele. They also studied 6 IDDM families, compared frequencies of the 4.2-kb allele in the probands and controls and demonstrated an increased relative risk associated with the 4.2 DR $\alpha$ allele compared to DR3 (11.8 vs. 5.5, respectively). They therefore concluded that the DR $\alpha$ polymorphism is a closer marker of IDDM than DR3 alone. This apparent discrepancy with our data might reflect either the increased numbers of IDDM subjects studied in our patient group (50 in our study versus 12 in Stetler's) or that Caucasian subjects in the United States and Britain have varying HLA-D region associations.

The DR $\alpha$ 3.8-kb fragment of the DR7 polymorphism was

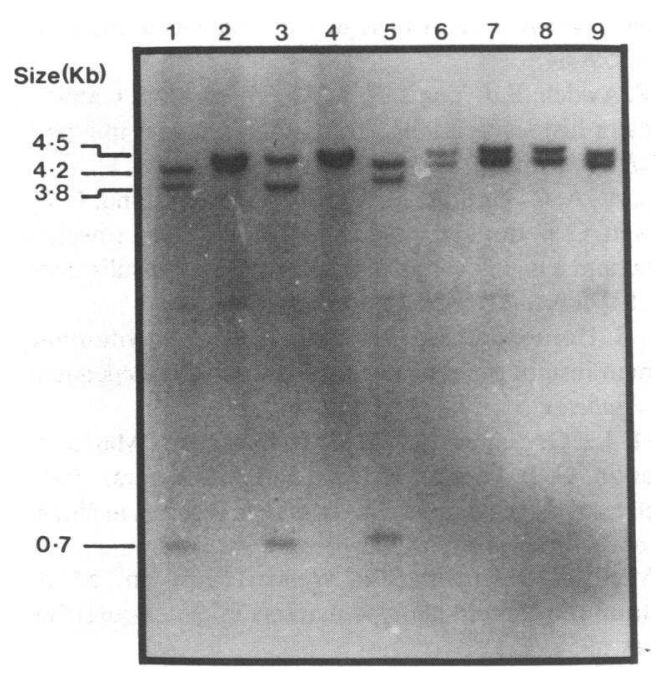

Figure 3. Autoradiogram of $\mathrm{DR} \alpha$ restriction fragment length polymorphism. DNA from nine individuals (labeled 1-9) was digested with Bgl II and studied by Southern blot hybridization methods using a cDNA $\mathrm{DR} \alpha$ probe. less frequent in patients with $\mathrm{CD}$ and $\mathrm{DH}$ compared with controls. This fragment is associated with the DR7-DQw3 haplotype which is also reduced, in favor of the DR7-DQw2 haplotype. The RFLP data based on the DR $\alpha$ polymorphism thus confirms the serological data aligning the disease susceptibility gene of this haplotype to the $\mathrm{DQ}$ region in CD patients.

Five different $\mathrm{DQ} \alpha$ related hybridization bands were detected as previously reported (18) not all of which correspond to DRDQw serological associations. The increased frequency of the 4.6-kb fragment in all three patient groups is a reflection of its DR3 association determined from controls. The DQw heterogeneity found in DR2 individuals is similar in all four groups. In DRw6 individuals, the 6.8-kb fragment occurs more frequently in the control and the CD patient groups, whereas the 6.2-kb fragment occurs at a higher frequency in the IDDM and DH patient groups (although the numbers involved are too few to establish whether the differences are meaningful).

We have previously observed that the $2.1-\mathrm{kb}$ fragment $(U)$ of the DX $\alpha$ di-allelic Taq 1 polymorphism correlated with DR3 in population studies of control and IDDM patients and in family studies (18). We now find that the frequency of the UU genotype

Table V. RFLPs Associated with the DRa Probe

\begin{tabular}{llrllr}
\hline DR & RFLP & \multicolumn{1}{c}{ Control } & IDDM & DH & \multicolumn{1}{l}{ CD } \\
\hline & $k b$ & & & & \\
DR3* & 4.5 & $3(13 \%)$ & $4(15 \%)$ & $1(3 \%)$ & $3(11 \%)$ \\
& 4.2 & $20(87 \%)$ & $22(85 \%)$ & $28(97 \%)$ & $25(90 \%)$ \\
DR7 & 4.5 & $8(57 \%)$ & 3 & 7 & $15^{\ddagger}(88 \%)$ \\
& 3.8 & $6(43 \%)$ & 0 & 0 & $2^{\ddagger}(11 \%)$
\end{tabular}

* Excludes DR3/DRw6 individuals in whom it was not possible to assign the 4.5/4.2 fragments. $P$ values were calculated from $2 \times 2$ contingency tables by chi squares for comparison of patients with controls. $\ddagger P<0.05$. 
Table VI. Preferential Allelic Associations and Disease Susceptibility

\begin{tabular}{|c|c|c|c|c|c|c|c|c|c|c|}
\hline $\mathrm{DX} \alpha$ & & $\mathrm{DQ} \alpha$ & & DQw & & DR & & $\mathrm{DR} \alpha$ & B & $\begin{array}{l}\text { At risk of disease } \\
\text { association }\end{array}$ \\
\hline 2.1 & - & 6.2 & - & 1 & - & 2 & - & 4.5 & 7 & None \\
\hline 2.1 & - & 6.8 & - & 1 & - & 2 & - & 4.5 & - & None \\
\hline 2.1 & - & 4.6 & - & 2 & - & 3 & - & 4.2 & 8 & IDDM, CD, DH \\
\hline 1.9 & - & 4.6 & - & 2 & - & 3 & - & 4.5 & 8 & None \\
\hline 2.1 & - & 5.5 & - & 3 & - & 4 & - & 4.5 & 62 & IDDM \\
\hline 1.9 & - & 5.5 & - & 3 & - & 4 & - & 4.5 & 44 & $\operatorname{RA}(15)^{*}$ \\
\hline 2.1 & - & 6.2 & - & 1 & - & w6 & - & 4.5 & 一 & IDDM \\
\hline 2.1 & - & 6.8 & - & 1 & - & w6 & - & 4.5 & - & $\mathrm{CD}$ \\
\hline 1.9 & - & 5.5 & - & 2 & - & 7 & - & 4.5 & 一 & $\mathrm{CD}$ \\
\hline 1.9 & - & 5.5 & - & 3 & - & 7 & - & 3.8 & 57 & None \\
\hline
\end{tabular}

* RA, rheumatoid arthritis.

in DH and CD as well as IDDM is significantly raised compared with controls (CD 56\%, DH 50\%, IDDM 57\% vs. controls $21 \%$; $P<0.001$ for all comparisons).

We have previously suggested that no single gene product encoded by the MHC gene is responsible for the pathogenesis of IDDM but that several genes in linkage disequilibrium with each other can be implicated (15). We therefore correlated all the common DR antigens with either the $U$ or $L$ allele by studying individuals homozygous at the $\mathrm{DX} \alpha$ locus. In all subjects the $\mathrm{U}$ allele was associated with DR 3 and DR $\alpha 4.2 \mathrm{~kb}$ but failed to differentiate patients from controls. Thus the exact location within the HLA-D region of the DR3 related disease susceptibility gene cannot be determined from our investigations. The increased frequency of the UU genotype in IDDM can now be explained by an increased association of DR4 with the $U$ allele in contrast to controls, as well as a consequence of the increased frequency of U-DR3 in this condition.

It has been suggested that the DQ and DX are neighboring loci on chromosome 6 (17). In addition to the IDDM DR4$\mathrm{DX} \alpha \mathrm{U}$ association, we have also described an IDDM associated DQ $\beta$ gene polymorphism that identifies a subset of DR4 (15). In a preliminary study we have examined the frequency of $\mathrm{DX} \alpha$ genotypes in those subjects with the high risk $D Q \beta$ polymorphism (designated omega [15] and characterized by Taq 1 fragments sized 2.0, 2.3, and $2.5 \mathrm{~kb}$ ). Of 48 subjects who possessed the omega pattern, $39.5 \%$ were UU, $39.5 \%$ UL and $21 \%$ LL. As at least one-fifth of DR4 subjects who possess omega do not possess $\mathrm{DX} \alpha \mathrm{U}$, this implies that there is either a recombinational hot spot between DQ and DX loci or that these loci are independent with respect to susceptibility to IDDM. The formation of MHC mixed isotypic dimers has been recently observed in the murine model by Germain and Quill (29) and has been hypothesised as a mechanism of disease susceptibility. One intriguing possibility therefore to explain this data is that in IDDM $\mathrm{DX} \alpha$ and $\mathrm{DQ} \beta$ genes (or genes in linkage disequilibrium with one or both of them) code for products which form a dimer molecule of etiological significance in this disease.

The increased frequency of the UU genotype in $\mathrm{CD}$ and $\mathrm{DH}$ is more difficult to account for in terms of DR antigen associations (Table IV). Thus a possibility is that the second non-DR3 related $U$ allele is the primary genetic determinant rather than $\mathrm{DR} 2$ or DR7 in DH and CD, respectively.
The serological and RFLP data point to the DR4, DR2, and DR7 related genes involved in the immunopathogenesis of IDDM, DH and CD, respectively, being located in the HLADQ (which includes the DX genes) rather than the DR MHC sub-region.

\section{Acknowledgments}

We thank Professor Robert Cohen for support and helpful advice and Drs. Barbara Boucher and John Monson for allowing access to their patients, Ms. Julie Ogilvie for technical assistance and Miss Christine Taylor for preparation of the manuscript.

The following grant awarding institutions are acknowledged: The Research Advisory Committee, The London Hospital, The Central Research Fund (Powell Trust), The University of London, Nordisk U.K., The Wellcome Trust, Coeliac Trust and the Medical Research Council.

\section{References}

1. Thomsen, M., P. Platz, O. O. Anderson, M. Christy, J. Lyngsoe, J. Nerup, K. Rasmussen, L. P. Ryder, L. S. Nielsen, and A. Svejgaard. 1975. MLC typing in juvenile diabetes mellitus and idiopathic Addison's disease. Transplant Rev. 22:120-147.

2. Cudworth, A. G., and H. Festenstein. 1984. HLA genetic heterogeneity in diabetes mellitus. Br. Med. Bull. 34:285-290.

3. Sachs, J. A., A. G. Cudworth, D. Jaraquemada, A. N. Gorsuch, and H. Festenstein. 1980. Type 1 diabetes and the HLA-D locus. Diabetologia. 418:41-43.

4. Sachs, J. A., J. Awad, D. McCloskey, C. Navarette, H. Festenstein, E. Elliot, J. A. Walker-Smith, C. E. M. Griffiths, J. N. Leonard, and L. Fry. 1986. Different HLA associated gene combinations contribute to susceptibility for coeliac disease and dermatitis herpetiformis. Gut. 27: 515-520.

5. De Marchi, M., I. Burelli, E. Olivetti, P. Richiardi, P. Wright, N. Ansaldi, C. Barberi, and B. Santini. 1979. Two HLA-DR alleles are associated with coeliac disease. Tissue Ant. 14:309-316.

6. Scholz, S., and Albert, E. 1983. HLA and disease: involvement of more than one HLA linked determinant of disease susceptibility. Immunol. Rev. 70:77-88.

7. Schauf, V., S. Ryan, D. Scollard, O. Jonasson, A. Brown, K. Nelson, T. Smith, and V. Vithayasai. 1985. Leprosy associated with HLA DR2 and DQw1 in the population of Northern Thailand. Tissue Antigen. 26: 243-247.

8. Bach, F. H., S. S. Rich, J. Barbosa, and M. Segall. 1984. Insulin dependent diabetes associated HLA-D region encoded determinants. Hum. Immunol. 12:59-64.

9. Raum, D., Z. Awdeh, E. J. Yunis, C. A. Alper, and K. H. Gabbay. 1984. Extended major histocompatibility complex haplotypes in type 1 diabetes mellitus. J. Clin. Invest. 74:449-454.

10. Hitman, G. A., A. C. Tarn, R. M. Winter, V. Drummond, L. G. Williams, N. I. Jowett, G. F. Bottazzo, and D. J. Galton. Type 1 (insulindependent) diabetes and a highly variable locus close to the insulin gene on chromosome 11. Diabetologia. 28:218-222.

11. Bell, G. I., S. Horito, and J. H. Karam. 1984. A polymorphic locus near the human insulin gene is associated with insulin dependent diabetes mellitus. Diabetes. 33:176-183.

12. Hoover, M. L., G. Angelini, E. Ball, P. Stastny, J. Marks, J. Rosenstock, P. Raskin, G. B. Ferrara, R. Tosi, and J. D. Capra. 1986. HLA-DQ and T cell receptor genes in insulin dependent diabetes mellitus. Cold Spring Harbor Symp. Quant. Biol. In press.

13. Kagnoff, M. F., R. J. Brown, J. B. Weiss, T. Lee, and M. S. Schenfield. 1983. Immunoglobulin allotype markers in gluten-sensitive enteropathy. Lancet. i:952-953.

14. Owerbach, D., A. Lernmark, P. Platz, L. P. Ryder, L. Rask, P. A. Peterson, and J. Ludvigsson. 1983. HLA-D region $\beta$ chain DNA endonuclease fragments differ between HLA-DR identical healthy and insulin-dependent diabetic individuals. Nature (Lond.). 303:815-817.

15. Festenstein, H., J. Awad, G. A. Hitman, S. Cutbush, A. V. Groves, 
P. Cassell, W. Ollier, and J. A. Sachs. 1986. New HLA DNA polymorphisms associated with auto-immune diseases. Nature (Lond.). 322:6467.

16. Cohen-Haguenauer, O., E. Robbins, C. Massart, M. Bussom, I. Deschamps, J. Hors, J. Lalouel, J. Dausset, and D. Cohen. 1985. A systematic study of the HLA class II $\beta$ DNA restriction fragments in insulin dependent diabetes mellitus. Proc. Natl. Acad. Sci. USA. 82:33353339.

17. Okada, K., J. M. Boss, H. Prentice, T. Spies, R. Mengler, C. Auffray, J. Lillie, D. Grossberger, and J. L. Strominger. 1985. Gene organisation of DC and DX subregions of the human major histocompatibility complex. Proc. Natl. Acad. Sci. USA. 82:3410-3414.

18. Hitman, G. A., J. Sachs, P. Cassell, J. Awad, G. F. Bottazzo, A. C. Tarn, G. Schwartz, J. P. Monson, and H. Festenstein. 1986. A DR3-related DX $\alpha$ gene polymorphism strongly associates with insulindependent diabetes mellitus. Immunogenetics. 23:47-51.

19. Okoye, R. C., E. Williams, A. Alonso, P. Doyle, J. Awad, C. Navarette, J. Jaraquemada, W. E. Ollier, and H. Festenstein. 1985. HLA polymorphisms in Nigerians. Tissue Antigens. 25:142-155.

20. Hitman, G. A., N. I. Jowett, L. G. Williams, S. Humphries, R. M. Winter, and D. J. Galton. 1984. Polymorphisms in the 5'-flanking region of the insulin gene and non-insulin dependent diabetes. Clin. Sci. 66:383-388.

21. Reed, K. C., and D. A. Mann. 1985. Rapid transfer of DNA from agarose gels to nylon membranes. Nucl. Acid Res. 13:7207-7221.

22. Spielman, R. S., J. Lee, W. F. Bodmer, J. G. Bodmer, and J. Trowsdale. 1984. Six HLA-D region $\alpha$ chain genes on human chromosome 6: polymorphisms and associations of $\mathrm{DC} \alpha$-related sequences with DR types. Proc. Natl. Acad. Sci. USA. 81:3461-3465.
23. Larhammer, D., K. Gustatsson, L. Claesson, P. Bull, K. Wiman, L. Schenning, J. Sundelin, E. Widmak, P. A. Peterson, and L. Rask. 1982. Alpha chain of HLA-DR transplantation antigen is a member of the same protein superfamily as the immunoglobulins. Cell. 30:153161.

24. Festenstein, H., F. Adam, J. Burke, R. T. D. Oliver, J. A. Sachs, and E. Wolf. 1972. In The distribution of HLA antigens in expatriates from East Bengal living in London. J. Dausset, editor. Histocompatibility Testing 1972, pp. 175-178, Munksgaard, Copenhagen.

25. van Rood, J. J., A. van Leeuwen, and J. S. Ploem. 1976. Simultaneous detection of two cell populations by two color fluorescence and application on the recognition of B cell determinants. Nature (Lond.). 262:795-797.

26. Tosi, R., D. Vosmara, N. Tanigaki, G. B. Ferrar, F. Cicimarra, V. Y. Buffolawd, D. Follo, and S. Aurrichio. 1983. Evidence that coeliac disease is primarily associated with a DC locus allelic specificity. Clin. Immunol. Immunopathol. 28:395-404.

27. Alonzo, A. D. R., D. Jaraquemada, W. Ollier, C. Navarette, and H. Festenstein. 1984. $\alpha$ and $\beta$ chain polymorphisms of HLA-DR4 antigens. Disease Markers. 2:119-126.

28. Stetler, D., F. C. Grumet, and H. A. Erlich. 1985. Polymorphic restriction endonuclease sites linked to the HLA-DR $\alpha$ gene: localization and use as genetic markers of insulin-dependent diabetes. Proc. Natl. Acad. Sci. USA. 82:8100-8104.

29. Germain, R. N. and H. Quill. 1986. Unexpected expression of a unique mixed-isotype Class II MHC molecule by transfected L-cells. Nature (Lond.). 320:72-75.

30. Niven, M. J. and G. A. Hitman. 1986. The molecular genetics of diabetes mellitus. Biosci. Rep. 6:501-512. 